\title{
Innovation Continuity as Indicator for Observing Stock Return Rate in China Stock Market
}

\author{
Hong-Wen Tsai ${ }^{1}$, Hui-Chung $\mathrm{Che}^{2}$ and $\mathrm{Bo} \mathrm{Bai}^{3}$
}

\begin{abstract}
Based on the patent data and stock return rates of thousands of China listed companies (A-shares), the effect of the innovation continuity which representing by the patent publication frequency, on the stock return rate were analyzed via ANOVA. The innovation continuity was good for observing the stock return rate in the whole market, Shanghai main board and small-medium board. The A-shares with the stronger innovation continuity showed the higher stock return rate. The utility model grant's innovation continuity was an indicator of the highest applicability. It could be applied for the whole market and any stock board. The design grant's strongest innovation continuity group had the highest stock return rate mean among all patent species' strongest innovation continuity groups 5 though the design grant was usually regarded as the most valueless patent species in China. The invention grant was always regarded as the most valuable patent species around the world, yet the stock return rate variance between the strongest innovation continuity groups of the invention grant and the invention publication was not significantly different. The invention publication's innovation continuity was more recommended rather than the invention grant's innovation continuity.
\end{abstract}

JEL classification numbers: C12, G11.

Keywords: Patent, China A-share, Innovation Continuity, ANOVA, Stock Price, Return Rate.

\footnotetext{
${ }^{1}$ Graduate Institute of Patent, National Taiwan University of Science and Technology, Taipei, Taiwan.

${ }^{2}$ Graduate Institute of Patent, National Taiwan University of Science and Technology, Taipei, Taiwan.

${ }^{3}$ Shenzhen TekGlory Intellectual Property Data Technologies, Ltd. Shenzhen, China.
} 


\section{Introduction}

Innovation is an essential driver of economic progress that benefits consumers, businesses and the economy as a whole. Most economists agree that technological innovation is a key driver of economic growth and the stock market usually reflects the economic conditions of an economy.

Via the positive innovation policy of government, China has been the largest patent application country in the world for years. China patent database is also the world's largest patent database. Meanwhile, China is now the world No.2 economy and having a stock market with the world No.2 transaction volume. The patents of listed companies in the stock market catch more attention than those of unlisted companies and individuals.

For China patent and stock market, earlier research suggested that China patent statistics are meaningful indicators because China patent count is correlated with R\&D input and financial output (Dang and Motohashi, 2015 [1]). It was found difficulty in integrating Chinese patent data with company data, however, the China patent database of all China listed companies and their subsidiaries from 1990 to 2010 was first time constructed (He, Tong, Zhang and He, 2016 [2]). By using the stock price data and patent data from 2011 to 2017 of China listed companies of RMB common stocks (A-shares) in Shanghai main board ( $\mathrm{SH}$ main board), the patent indicators' leading effect on the stock price was proved (Chen, Wei and Che, 2018 [3]).

The China A-shares are listed on four stock boards including $\mathrm{SH}$ main board, Shenzhen main board (SZ main board), Growing-Enterprises board (GE board) and Small-and-Medium Enterprises board (SME board). Via the patent indicators of ten years' patent data and the financial data of China A-shares from 2016Q4 to 2018Q3, the patent prediction equations for predicting the stock price, return-on-asset (ROA), return-on-equity (ROE), book-value-per-share (BPS), earnings-per-share (EPS), price-to-book $(\mathrm{PB})$ and price-to-earnings $(\mathrm{PE})$ over the whole stock market and each stock board were proposed and showed the excellence on the investment (Chiu, Chen and Che, 2020 [4, 5, 6, 7, 8, 9]; Li, Deng and Che, 2020 [11, 12]; Chiu, Chen and Che, 2021 [10]; Li, Deng and Che, 2021 [13]). It was further found that China A-shares having new patents of any patent species shown the higher stock price mean and the higher stock return rate mean than those A-shares having no new patents (Tsai, Che and Bai, 2021 [14])

Patent is the outcome of company's R\&D, the patent growth rate was proposed as the company's commitment to R\&D (Deng, Lev and Narin, 1999 [15]; Thomas, 2001 [16]). However, the significant relationship of the patent growth and company's financial performance has not be established. By modifying the patent growth rate, the innovation continuity is proposed in this research as the continuous patent publication behaviour. It is the objective of this research to find out whether the innovation continuity of any patent species has significant effect on the stock return rate of China A-shares or not. 


\section{Methodology}

\subsection{Patent Species}

There are four species of published patents in China including the invention publication, the utility model grant, the design grant, and the invention grant. The invention grant which being the only species passing both the preliminary examination and the substantial examination is always regarded as the most valuable. The other three patent species just need to pass the preliminary examination, wherein, the design grant is usually regarded as the most valueless patent species. After a patent is granted, the annual fee must be paid to the government regularly to maintain its validity. The valid patents are therefore regarded as more important than the invalid patents. In this research, the valid China patent of each A-share over previous five years by the end of each quarter from 2020Q1 to 2020Q4 are observed and discussed.

\subsection{Population and Sample}

The population comprises China A-shares listed in four stock boards including $\mathrm{SH}$ main board, SZ main board, GE board, and SME board. An effective sample must meet two conditions:

1. It is listed and has the exact closing price at the last trading day of each quarter from 2019 to 2020; and

2. It has at least one patent published over previous five years by the end of each quarter in 2020.

For those A-shares whose subsidiaries' revenue merged with the parent company in the annual report, the patents of such parent company are merged with those of the subsidiaries for observation.

For avoiding the survivor bias, the annual stock return rates at the last trading day of four quarters in 2020 are calculated. For 2020Q1, the stock return rate of each Ashare is calculated by the closing prices of the last trading day of 2019Q1 and 2020Q1. For 2020Q2, the stock return rate of each A-share is calculated by the closing prices of the last trading day of 2019Q2 and 2020Q3. And so forth for 2020Q3 and 2020Q4.

For discussing the innovation continuity, the annual publication frequency of patents is more concerned than either the amount of patents or the patent growth date. Therefore, five groups of innovation continuity are defined in this research. The group 1 consists of the A-shares having patent(s) published in only one year over previous five years by the end of each quarter in 2020; The group 2 consists of the A-shares having patents published in two different years over previous five years by the end of each quarter in 2020; the groups 3, 4, 5 and so forth. Hence, the group 1 is of the weakest innovation continuity while the group 5 is of the strongest innovation continuity.

\subsection{Analysis of Variance (ANOVA)}

Analysis of Variance (ANOVA) is applied for discovering whether the innovation 
continuity good for observing the stock return rate or not. ANOVA is a statistical approach used to compare variances across the means of different data groups. The outcome of ANOVA is the "F-statistic".

$$
F=\frac{M S T}{M S E}=\frac{\sum n_{j}\left(\overline{x_{j}}-\bar{x}\right) /(k-1)}{\sum \sum\left(x-\overline{x_{j}}\right)^{2} /(N-k)}
$$

This ratio shows the difference between the within group variance and the between group variance, which ultimately produces a result which allowing a conclusion that the null hypothesis $\mathrm{H} 0: \mu 1=\mu 2=\ldots .=\mu \mathrm{k}$ is supported or rejected. If there is a significant difference between the groups, the null hypothesis is not supported, and the F-ratio will be larger and the corresponding $\mathrm{p}$ value is smaller than 0.05 .

\section{Results and Analysis}

Table 1 shows the number of effective samples comprised in each innovation continuity group over the stock boards and four patent species, wherein, the whole market consists of all effective samples in four stock boards. Regarding the invention publication, the invention grant, and the utility model grant, the groups 5 have the most numbers of effective samples no matter what stock board and have a proportion around $50 \%$ or so of all effective samples. Regarding the design grant, the group 1 has the most number of effective samples. The A-shares showing stronger innovation continuity are much more than those A-shares having weaker innovation continuity.

Table 1: Effective Samples of Innovation Continuity Groups

\begin{tabular}{|c|c|c|c|c|c|c|}
\hline \multirow{2}{*}{ Patent Species } & \multirow{2}{*}{ Stock Board } & \multicolumn{5}{|c|}{ Effective Samples } \\
\cline { 3 - 7 } & & Group 1 & Group 2 & Group 3 & Group 4 & Group 5 \\
\hline \multirow{4}{*}{$\begin{array}{c}\text { Invention } \\
\text { Publication }\end{array}$} & Whole Market & 1206 & 1337 & 1387 & 2070 & 6353 \\
\cline { 2 - 7 } & SH Main Board & 569 & 597 & 545 & 765 & 2243 \\
\cline { 2 - 7 } & SZ Main Board & 181 & 182 & 157 & 178 & 698 \\
\cline { 2 - 7 } & GE Board & 213 & 267 & 343 & 582 & 1481 \\
\cline { 2 - 7 } & SME Board & 243 & 291 & 342 & 545 & 1931 \\
\hline \multirow{4}{*}{ Invention Grant } & Whole Market & 1536 & 1439 & 1565 & 1978 & 5148 \\
\cline { 2 - 7 } & SH Main Board & 671 & 604 & 579 & 689 & 1810 \\
\cline { 2 - 7 } & SZ Main Board & 206 & 160 & 146 & 151 & 605 \\
\cline { 2 - 7 } & GE Board & 297 & 301 & 425 & 587 & 1183 \\
\cline { 2 - 7 } Grant & SME Board & 362 & 374 & 415 & 551 & 1550 \\
\hline & Whole Market & 1354 & 1176 & 1292 & 1830 & 6248 \\
\cline { 2 - 7 } & SH Main Board & 627 & 479 & 528 & 742 & 2219 \\
\cline { 2 - 7 } & SZ Main Board & 223 & 152 & 130 & 150 & 718 \\
\cline { 2 - 7 } & GE Board & 290 & 258 & 296 & 453 & 1366 \\
\cline { 2 - 7 } & SME Board & 214 & 287 & 338 & 485 & 1945 \\
\hline & Whole Market & 2176 & 1369 & 1102 & 1068 & 1810 \\
\cline { 2 - 6 } Design Grant & SH Main Board & 904 & 534 & 406 & 337 & 630 \\
\cline { 2 - 6 } & SZ Main Board & 271 & 162 & 100 & 109 & 244 \\
\cline { 2 - 6 } & GE Board & 443 & 334 & 288 & 285 & 345 \\
\cline { 2 - 6 } & SME Board & 558 & 339 & 308 & 337 & 591 \\
\hline
\end{tabular}




\subsection{Invention Publication}

Table 2 shows the results of ANOVA on the stock return rate between the invention publication's innovation continuity groups. The stock return rate variances in the whole market and most stock boards reach $\mathrm{p}^{* * *} \leq 0.001$ significance; different invention publication's innovation continuity groups have significantly different stock return rate means. However, the stock return rate variance in GE board is not of significance.

Table 2: Result of ANOVA on Stock Return Rate Between Invention Publication's Innovation Continuity Groups

\begin{tabular}{|c|c|c|c|c|c|}
\hline Stoc & k Board & Sum & Mean & $\mathbf{F}$ & $\mathbf{p}$ \\
\hline Whole & between groups & 168578.7 & 42144.7 & 15.930 & $0.001 * * *$ \\
\hline & within groups & 32668262.0 & 2645.6 & & \\
\hline & all & 32836840.7 & & & \\
\hline SH Main & between groups & 82057.6 & 20514.4 & 9.516 & $0.001 * * *$ \\
\hline & within groups & 10161839.4 & 2155.7 & & \\
\hline & all & 10243897.0 & & & \\
\hline SZ Main & between groups & 52769.9 & 13192.5 & 9.430 & $0.001 * * *$ \\
\hline & within groups & 1946079.4 & 1399.1 & & \\
\hline & all & 1998849.4 & & & \\
\hline GE Board & between groups & 13179.7 & 3294.9 & 0.874 & 0.479 \\
\hline & within groups & 10865182.6 & 3771.3 & & \\
\hline & all & 10878362.3 & & & \\
\hline SME Board & between groups & 104984.0 & 26246.0 & 9.538 & $0.001 * * *$ \\
\hline & within groups & 9210127.0 & 2751.8 & & \\
\hline & all & 9315110.9 & & & \\
\hline
\end{tabular}

Table 3 shows the descriptive statistics of the stock return rates of five invention publication's innovation continuity groups. For the whole market and most stock boards except GE board, the groups 5 seem to have the higher stock return rate means than the other groups. For GE board, the group 1 seems to have the higher stock return rate mean. 
Table 3: Descriptive Statistics of Stock Return Rate of Invention Publication's Innovation Continuity Groups

\begin{tabular}{|c|c|c|c|c|}
\hline \multirow[b]{2}{*}{ Stock Board } & \multirow[b]{2}{*}{ Group } & \multicolumn{3}{|c|}{ Stock Return Rate (\%) } \\
\hline & & Mean & $\begin{array}{l}\text { Standard } \\
\text { Deviation }\end{array}$ & $\begin{array}{c}\text { Standard } \\
\text { Error }\end{array}$ \\
\hline \multirow{5}{*}{$\begin{array}{l}\text { Whole } \\
\text { Market }\end{array}$} & 1 & 2.380 & 46.367 & 1.335 \\
\hline & 2 & 6.224 & 48.172 & 1.317 \\
\hline & 3 & 6.205 & 61.252 & 1.645 \\
\hline & 4 & 7.714 & 51.611 & 1.134 \\
\hline & 5 & 12.853 & 50.604 & 0.635 \\
\hline \multirow{5}{*}{$\begin{array}{l}\text { SH Main } \\
\text { Board }\end{array}$} & 1 & -5.282 & 35.431 & 1.485 \\
\hline & 2 & 4.835 & 44.294 & 1.813 \\
\hline & 3 & 7.562 & 57.211 & 2.451 \\
\hline & 4 & 6.488 & 49.392 & 1.786 \\
\hline & 5 & 7.878 & 45.468 & 0.960 \\
\hline \multirow{5}{*}{$\begin{array}{l}\text { SZ Main } \\
\text { Board }\end{array}$} & 1 & -0.970 & 38.356 & 2.851 \\
\hline & 2 & -3.257 & 36.598 & 2.713 \\
\hline & 3 & -8.952 & 29.636 & 2.365 \\
\hline & 4 & -3.905 & 34.979 & 2.622 \\
\hline & 5 & 7.515 & 39.459 & 1.494 \\
\hline \multirow[t]{5}{*}{ GE Board } & 1 & 21.241 & 57.985 & 3.973 \\
\hline & 2 & 16.775 & 60.004 & 3.672 \\
\hline & 3 & 17.519 & 87.381 & 4.718 \\
\hline & 4 & 15.302 & 59.874 & 2.482 \\
\hline & 5 & 20.262 & 55.144 & 1.433 \\
\hline \multirow{5}{*}{ SME Board } & 1 & 6.286 & 56.955 & 6.286 \\
\hline & 2 & 5.324 & 48.541 & 5.324 \\
\hline & 3 & -0.347 & 41.082 & -0.347 \\
\hline & 4 & 5.127 & 48.613 & 5.127 \\
\hline & 5 & 14.881 & 55.200 & 14.881 \\
\hline
\end{tabular}

Table 4 shows the multiple comparisons of ANOVA on the stock return rate between every two invention publication's innovation continuity groups. Regarding the whole market, the stock return rate variances between groups 4 and 1, between groups 5 and 1, between groups 5 and 2, between groups 5 and 3, between groups 5 and 4 , are of significance; the others are not. The group 5 is confirmed to have the highest stock return rate mean among all groups according to the significant mean differences. However, the stock return rate ranking of groups 1,2, 3 and 4, is not provided with significance.

Regarding SH main board, the stock return rate variances between groups 2 and 1, between groups 3 and 1, between groups 4 and 1, between groups 5 and 1, are of significance; the others are not. The group 1 is therefore confirmed to have the 
lowest stock return rate mean among all groups according to the significant mean differences. However, the stock return rate ranking of groups 2, 3, 4 and 5, is not provided with significance.

Regarding SZ main board, the stock return rate variances between groups 5 and 1, between groups 5 and 2, between groups 5 and 3, between groups 5 and 4, are of significance; the others are not. The group 5 is therefore confirmed to have the highest stock return rate mean among all groups according to the significant mean differences. However, the stock return rate ranking of groups 1, 2, 3 and 4, is not provided with significance.

Regarding GE board, as shown in Tables 2 and 4, the stock return rate variances between any two groups are not of significance. The stock return rates in groups 1 , 2, 3, 4 and 5, do not show significant difference.

Regarding SME board, the stock return rate variances between groups 5 and 1, between groups 5 and 2, between groups 5 and 3, between groups 5 and 4, are of significance; the others are not. The group 5 is therefore confirmed to have the highest stock return rate mean among all groups according to the significant mean differences. However, the stock return rate ranking of groups 1, 2, 3 and 4, is not provided with significance.

According to the above analyses, the invention publication's innovation continuity is a good indicator for observing the stock return rate. The stock return rate variances between the invention publication's innovation continuity groups are of significance in the whole market and most stock boards except GE board. The innovation continuity group 5 has the highest stock return rate though the stock return rate ranking of the other innovation continuity groups is not significant.

Table 4: Multiple Comparisons of ANOVA on Stock Return Rate between Invention Publication's Innovation Continuity Groups

\begin{tabular}{|c|c|c|c|c|c|}
\hline \multirow{4}{*}{ Stock Board } & \multirow{2}{*}{$\begin{array}{c}(\mathbf{I}) \\
\text { Group }\end{array}$} & $\begin{array}{c}(\mathbf{J}) \\
\text { Group }\end{array}$ & \multicolumn{3}{|c|}{ Stock Return Rate (\%) } \\
\cline { 4 - 6 } & & & $\begin{array}{c}\text { Mean Difference } \\
(\mathbf{I}-\mathbf{J})\end{array}$ & $\begin{array}{c}\text { Standard } \\
\text { Error }\end{array}$ & $\mathbf{p}$ \\
\hline \multirow{4}{*}{$\begin{array}{c}\text { Whole } \\
\text { Market }\end{array}$} & 2 & 1 & 3.844 & 2.043 & 0.060 \\
\cline { 2 - 6 } & 3 & 1 & 3.825 & 2.025 & 0.059 \\
\cline { 2 - 6 } & 3 & 2 & -0.019 & 1.971 & 0.992 \\
\cline { 2 - 6 } & 4 & 1 & 5.334 & 1.863 & $0.004^{* *}$ \\
\cline { 2 - 6 } & 4 & 2 & 1.490 & 1.805 & 0.409 \\
\cline { 2 - 6 } & 4 & 3 & 1.509 & 1.785 & 0.398 \\
\cline { 2 - 6 } & 5 & 1 & 10.473 & 1.616 & $0.001^{* * *}$ \\
\cline { 2 - 6 } & 5 & 2 & 6.629 & 1.548 & $0.001^{* * *}$ \\
\cline { 2 - 6 } & 5 & 3 & 6.648 & 1.524 & $0.001^{* * *}$ \\
\cline { 2 - 6 } & 5 & 4 & 5.139 & 1.302 & $0.001^{* * *}$ \\
\hline
\end{tabular}




\begin{tabular}{|c|c|c|c|c|c|}
\hline \multirow{10}{*}{$\begin{array}{l}\text { SH Main } \\
\text { Board }\end{array}$} & 2 & 1 & 10.117 & 2.720 & $0.001 * * *$ \\
\hline & 3 & 1 & 12.844 & 2.783 & $0.001 * * *$ \\
\hline & 3 & 2 & 2.727 & 2.751 & 0.322 \\
\hline & 4 & 1 & 11.770 & 2.570 & $0.001 * * *$ \\
\hline & 4 & 2 & 1.653 & 2.535 & 0.515 \\
\hline & 4 & 3 & -1.074 & 2.603 & 0.680 \\
\hline & 5 & 1 & 13.160 & 2.179 & $0.001 * * *$ \\
\hline & 5 & 2 & 3.042 & 2.138 & 0.155 \\
\hline & 5 & 3 & 0.315 & 2.217 & 0.887 \\
\hline & 5 & 4 & 1.390 & 1.944 & 0.475 \\
\hline \multirow{10}{*}{$\begin{array}{l}\text { SZ Main } \\
\text { Board }\end{array}$} & 2 & 1 & -2.287 & 3.926 & 0.560 \\
\hline & 3 & 1 & -7.982 & 4.079 & 0.051 \\
\hline & 3 & 2 & -5.695 & 4.074 & 0.162 \\
\hline & 4 & 1 & -2.935 & 3.948 & 0.457 \\
\hline & 4 & 2 & -0.648 & 3.943 & 0.870 \\
\hline & 4 & 3 & 5.047 & 4.095 & 0.218 \\
\hline & 5 & 1 & 8.485 & 3.120 & $0.007 * *$ \\
\hline & 5 & 2 & 10.772 & 3.113 & $0.001 * * *$ \\
\hline & 5 & 3 & 16.467 & 3.304 & $0.001 * * *$ \\
\hline & 5 & 4 & 11.420 & 3.141 & $0.001 * * *$ \\
\hline \multirow[t]{10}{*}{ GE Board } & 2 & 1 & -4.466 & 5.642 & 0.429 \\
\hline & 3 & 1 & -3.722 & 5.357 & 0.487 \\
\hline & 3 & 2 & 0.744 & 5.012 & 0.882 \\
\hline & 4 & 1 & -5.939 & 4.918 & 0.227 \\
\hline & 4 & 2 & -1.473 & 4.539 & 0.746 \\
\hline & 4 & 3 & -2.217 & 4.180 & 0.596 \\
\hline & 5 & 1 & -0.978 & 4.500 & 0.828 \\
\hline & 5 & 2 & 3.488 & 4.083 & 0.393 \\
\hline & 5 & 3 & 2.743 & 3.680 & 0.456 \\
\hline & 5 & 4 & 4.961 & 3.004 & 0.099 \\
\hline \multirow[t]{10}{*}{ SME Board } & 2 & 1 & -0.962 & 4.559 & 0.833 \\
\hline & 3 & 1 & -6.633 & 4.401 & 0.132 \\
\hline & 3 & 2 & -5.671 & 4.184 & 0.175 \\
\hline & 4 & 1 & -1.159 & 4.046 & 0.775 \\
\hline & 4 & 2 & -0.197 & 3.809 & 0.959 \\
\hline & 4 & 3 & 5.474 & 3.619 & 0.130 \\
\hline & 5 & 1 & 8.594 & 3.571 & $0.016^{*}$ \\
\hline & 5 & 2 & 9.556 & 3.299 & $0.004 * *$ \\
\hline & 5 & 3 & 15.227 & 3.078 & $0.001 * * *$ \\
\hline & 5 & 4 & 9.753 & 2.544 & $0.001 * * *$ \\
\hline
\end{tabular}

$\mathrm{p}^{*}<0.05, \mathrm{p}^{* *} \leq 0.01, \mathrm{p}^{* * *} \leq 0.001$ 


\subsection{Invention Grant}

Table 5 shows the results of ANOVA on the stock return rate between the invention grant's innovation continuity groups. The stock return rate variances reach $\mathrm{p}^{* * *} \leq 0.001$ significance in the whole market, SZ main board, SME board, and $\mathrm{p}<0.05$ significance in SH main board. Different invention grant's innovation continuity groups have significantly different stock return rate means in the whole market and the aforementioned stock boards. However, the stock return rate variance in GE board is not of significance.

Table 5: Result of ANOVA on Stock Return Rate Between Invention Grant's Innovation Continuity Groups

\begin{tabular}{|c|c|c|c|c|c|}
\hline \multicolumn{2}{|c|}{ Stock Board } & Sum Square & Mean Square & $\mathbf{F}$ & $\mathbf{p}$ \\
\hline \multirow[t]{3}{*}{$\begin{array}{l}\text { Whole } \\
\text { Market }\end{array}$} & $\begin{array}{c}\text { between } \\
\text { groups }\end{array}$ & 83651.5 & 20912.9 & 7.705 & $0.001 * * *$ \\
\hline & within groups & 31650880.7 & 2714.3 & & \\
\hline & all & 31734532.2 & & & \\
\hline \multirow[t]{3}{*}{$\begin{array}{l}\text { SH Main } \\
\text { Board }\end{array}$} & $\begin{array}{c}\text { between } \\
\text { groups }\end{array}$ & 21897.5 & 5474.4 & 2.399 & $0.048 *$ \\
\hline & within groups & 9923527.6 & 2282.3 & & \\
\hline & all & 9945425.1 & & & \\
\hline \multirow[t]{3}{*}{$\begin{array}{l}\text { SZ Main } \\
\text { Board }\end{array}$} & $\begin{array}{l}\text { between } \\
\text { groups }\end{array}$ & 59282.9 & 14820.7 & 11.211 & $0.001 * * *$ \\
\hline & within groups & 1669599.3 & 1321.9 & & \\
\hline & all & 1728882.2 & & & \\
\hline \multirow[t]{3}{*}{ GE Board } & $\begin{array}{c}\text { between } \\
\text { groups }\end{array}$ & 24797.8 & 6199.4 & 1.638 & 0.162 \\
\hline & within groups & 10550078.4 & 3784.1 & & \\
\hline & all & 10574876.2 & & & \\
\hline \multirow[t]{3}{*}{ SME Board } & $\begin{array}{c}\text { between } \\
\text { groups }\end{array}$ & 94517.5 & 23629.4 & 8.529 & $0.001 * * *$ \\
\hline & within groups & 8995239.2 & 2770.3 & & \\
\hline & all & 9089756.7 & & & \\
\hline
\end{tabular}

Table 6 shows the descriptive statistics of the stock return rates of five invention grant's innovation continuity groups. For the whole market, SZ main board and SME board, the groups 5 seem to have the higher stock return rate means than the other groups; whereas the groups 5 in SH main board and GE board do not. 
Table 6: Descriptive Statistics of Stock Return Rate of Invention Grant's Innovation Continuity Groups

\begin{tabular}{|c|c|c|c|c|}
\hline \multirow[b]{2}{*}{ Stock Board } & \multirow[b]{2}{*}{ Group } & \multicolumn{3}{|c|}{ Stock Return Rate (\%) } \\
\hline & & Mean & Standard Deviation & $\begin{array}{c}\text { Standard } \\
\text { Error }\end{array}$ \\
\hline \multirow{5}{*}{$\begin{array}{l}\text { Whole } \\
\text { Market }\end{array}$} & 1 & 7.723 & 53.036 & 1.353 \\
\hline & 2 & 6.168 & 58.975 & 1.555 \\
\hline & 3 & 7.884 & 49.117 & 1.242 \\
\hline & 4 & 8.998 & 50.597 & 1.138 \\
\hline & 5 & 12.978 & 51.209 & 0.714 \\
\hline \multirow{5}{*}{$\begin{array}{l}\text { SH Main } \\
\text { Board }\end{array}$} & 1 & 5.660 & 52.594 & 2.030 \\
\hline & 2 & 3.056 & 47.423 & 1.930 \\
\hline & 3 & 8.654 & 53.249 & 2.213 \\
\hline & 4 & 3.619 & 42.483 & 1.618 \\
\hline & 5 & 8.299 & 46.034 & 1.082 \\
\hline \multirow{5}{*}{$\begin{array}{l}\text { SZ Main } \\
\text { Board }\end{array}$} & 1 & -7.363 & 27.062 & 1.886 \\
\hline & 2 & -8.871 & 30.255 & 2.392 \\
\hline & 3 & -4.833 & 32.334 & 2.676 \\
\hline & 4 & 4.797 & 41.121 & 3.346 \\
\hline & 5 & 7.050 & 40.047 & 1.628 \\
\hline \multirow[t]{5}{*}{ GE Board } & 1 & 22.544 & 59.528 & 3.454 \\
\hline & 2 & 24.636 & 94.626 & 5.454 \\
\hline & 3 & 13.761 & 47.695 & 2.314 \\
\hline & 4 & 19.069 & 62.340 & 2.573 \\
\hline & 5 & 19.121 & 54.981 & 1.599 \\
\hline \multirow{5}{*}{ SME Board } & 1 & 7.972 & 56.450 & 2.967 \\
\hline & 2 & 2.766 & 42.211 & 2.183 \\
\hline & 3 & 5.266 & 48.571 & 2.384 \\
\hline & 4 & 6.148 & 46.749 & 1.992 \\
\hline & 5 & 16.068 & 56.824 & 1.443 \\
\hline
\end{tabular}

Table 7 shows the multiple comparisons of ANOVA on the stock return rate between every two invention grant's innovation continuity groups. Regarding the whole market, the stock return rate variances between groups 5 and 1, between groups 5 and 2, between groups 5 and 3, between groups 5 and 4, are of significance; the others are not. The group 5 is confirmed to have the highest stock return rate mean among all groups according to the significant mean differences. However, the stock return rate ranking of groups 1,2,3 and 4, is not provided with significance. Regarding SH main board, the stock return rate variances between groups 5 and 2, between groups 5 and 4, are of significance; the others are not. The group 5 is confirmed to have the higher but not the highest stock return rate mean among all 
groups according to the significant mean differences. In addition, the stock return rate ranking of groups 1, 2, 3 and 4, is not provided with significance..

Regarding SZ main board, the stock return rate variances between groups 4 and 1, between groups 4 and 2, between groups 4 and 3, between groups 5 and 1, between groups 5 and 2, between groups 5 and 3, are of significance; the others are not. The groups 4 and 5 are confirmed to have the higher stock return rate mean among all groups according to the significant mean differences. However, the stock return rate ranking of groups 1, 2, 3 and in groups 4, 5, is not provided with significance.

Regarding GE board, as shown in Tables 2 and 4, the stock return rate variance is only of significance between groups 3 and 2; the stock return rate variances between any other two groups are not of significance. The stock return rates in groups 1,2 , 3, 4 and 5, do not show significant difference.

Regarding SME board, the stock return rate variances between groups 5 and 1, between groups 5 and 2, between groups 5 and 3, between groups 5 and 4, are of significance; the others are not. The group 5 is therefore confirmed to have the highest stock return rate mean among all groups according to the significant mean differences. However, the stock return rate ranking of groups 1, 2, 3 and 4, is not provided with significance.

According to the above analyses, the invention grant's innovation continuity is a good indicator for observing the stock return rate in the whole market, SZ main board and SME board. The invention grant's innovation continuity group 5 has the higher stock return rate in the whole market, SZ main board and SME board, however, the stock return rate ranking of the other innovation continuity groups is not significant.

Table 7: Multiple Comparisons of ANOVA on Stock Return Rate between Invention Grant's Innovation Continuity Groups

\begin{tabular}{|c|c|c|c|c|c|}
\hline \multirow{2}{*}{ Stock Board } & \multirow{2}{*}{$\begin{array}{c}\text { (I) } \\
\text { Group }\end{array}$} & \multirow{2}{*}{$\begin{array}{c}(\mathbf{J}) \\
\text { Group }\end{array}$} & \multicolumn{3}{|c|}{ Stock Return Rate (\%) } \\
\hline & & & $\begin{array}{c}\text { Mean Difference } \\
\text { (I-J) }\end{array}$ & $\begin{array}{c}\text { Standard } \\
\text { Error }\end{array}$ & $\mathbf{p}$ \\
\hline \multirow[t]{10}{*}{ Whole Market } & 2 & 1 & -1.555 & 1.911 & 0.416 \\
\hline & 3 & 1 & 0.161 & 1.871 & 0.931 \\
\hline & 3 & 2 & 1.716 & 1.903 & 0.367 \\
\hline & 4 & 1 & 1.275 & 1.772 & 0.472 \\
\hline & 4 & 2 & 2.830 & 1.805 & 0.117 \\
\hline & 4 & 3 & 1.114 & 1.763 & 0.527 \\
\hline & 5 & 1 & 5.255 & 1.515 & $0.001 * * *$ \\
\hline & 5 & 2 & 6.810 & 1.554 & $0.001 * * *$ \\
\hline & 5 & 3 & 5.094 & 1.504 & $0.001 * * *$ \\
\hline & 5 & 4 & 3.980 & 1.378 & $0.004 * *$ \\
\hline
\end{tabular}




\begin{tabular}{|c|c|c|c|c|c|}
\hline \multirow[t]{10}{*}{ SH Main Board } & 2 & 1 & -2.604 & 2.680 & 0.331 \\
\hline & 3 & 1 & 2.993 & 2.710 & 0.269 \\
\hline & 3 & 2 & 5.598 & 2.779 & 0.044 \\
\hline & 4 & 1 & -2.041 & 2.591 & 0.431 \\
\hline & 4 & 2 & 0.563 & 2.663 & 0.832 \\
\hline & 4 & 3 & -5.034 & 2.693 & 0.062 \\
\hline & 5 & 1 & 2.639 & 2.159 & 0.222 \\
\hline & 5 & 2 & 5.243 & 2.245 & $0.020^{*}$ \\
\hline & 5 & 3 & -0.354 & 2.281 & 0.877 \\
\hline & 5 & 4 & 4.680 & 2.139 & $0.029 *$ \\
\hline \multirow{10}{*}{ SZ Main Board } & 2 & 1 & -1.508 & 3.831 & 0.694 \\
\hline & 3 & 1 & 2.530 & 3.933 & 0.520 \\
\hline & 3 & 2 & 4.038 & 4.161 & 0.332 \\
\hline & 4 & 1 & 12.160 & 3.895 & $0.002 * *$ \\
\hline & 4 & 2 & 13.668 & 4.125 & $0.001 * * *$ \\
\hline & 4 & 3 & 9.630 & 4.220 & $0.023^{*}$ \\
\hline & 5 & 1 & 14.413 & 2.933 & $0.001 * * *$ \\
\hline & 5 & 2 & 15.921 & 3.232 & $0.001 * * *$ \\
\hline & 5 & 3 & 11.883 & 3.353 & $0.001 * * *$ \\
\hline & 5 & 4 & 2.253 & 3.307 & 0.496 \\
\hline \multirow[t]{10}{*}{ GE Board } & 2 & 1 & 2.092 & 5.031 & 0.678 \\
\hline & 3 & 1 & -8.783 & 4.652 & 0.059 \\
\hline & 3 & 2 & -10.875 & 4.634 & $0.019 *$ \\
\hline & 4 & 1 & -3.475 & 4.380 & 0.428 \\
\hline & 4 & 2 & -5.568 & 4.361 & 0.202 \\
\hline & 4 & 3 & 5.307 & 3.918 & 0.176 \\
\hline & 5 & 1 & -3.423 & 3.992 & 0.391 \\
\hline & 5 & 2 & -5.515 & 3.971 & 0.165 \\
\hline & 5 & 3 & 5.360 & 3.479 & 0.124 \\
\hline & 5 & 4 & 0.052 & 3.106 & 0.987 \\
\hline \multirow[t]{10}{*}{ SME Board } & 2 & 1 & -5.206 & 3.881 & 0.180 \\
\hline & 3 & 1 & -2.706 & 3.785 & 0.475 \\
\hline & 3 & 2 & 2.500 & 3.753 & 0.505 \\
\hline & 4 & 1 & -1.824 & 3.561 & 0.608 \\
\hline & 4 & 2 & 3.382 & 3.526 & 0.338 \\
\hline & 4 & 3 & 0.881 & 3.421 & 0.797 \\
\hline & 5 & 1 & 8.096 & 3.072 & $0.008^{* *}$ \\
\hline & 5 & 2 & 13.302 & 3.032 & $0.001 * * *$ \\
\hline & 5 & 3 & 10.801 & 2.909 & $0.001 * * *$ \\
\hline & 5 & 4 & 9.920 & 2.611 & $0.001 * * *$ \\
\hline
\end{tabular}

$\mathrm{p}^{*}<0.05, \mathrm{p}^{* *} \leq 0.01, \mathrm{p}^{* * *} \leq 0.001$ 


\subsection{Utility Model Grant}

Table 8 shows the results of ANOVA on the stock return rate between the utility model grant's innovation continuity groups. The stock return rate variances reach $\mathrm{p}^{* * *} \leq 0.001$ significance in the whole market, SH main board, GE board, SME board, and $\mathrm{p}^{* *} \leq 0.01$ significance in SZ main board. Different utility model grant's innovation continuity groups have significantly different stock return rate means.

Table 8: Result of ANOVA on Stock Return Rate Between Utility Model Grant's Innovation Continuity Groups

\begin{tabular}{|c|c|c|c|c|c|}
\hline \multicolumn{2}{|c|}{ Stock Board } & Sum Square & Mean Square & $\mathbf{F}$ & $\mathbf{p}$ \\
\hline \multirow[t]{3}{*}{ Whole Market } & between groups & 72408.7 & 18102.2 & 6.466 & $0.001 * * *$ \\
\hline & within groups & 33300338.7 & 2799.5 & & \\
\hline & all & 33372747.4 & & & \\
\hline \multirow[t]{3}{*}{ SH Main Board } & between groups & 45679.1 & 11419.8 & 5.313 & $0.001 * * *$ \\
\hline & within groups & 9865657.3 & 2149.4 & & \\
\hline & all & 9911336.4 & & & \\
\hline \multirow[t]{3}{*}{ SZ Main Board } & between groups & 22025.6 & 5506.4 & 3.750 & $0.005 * *$ \\
\hline & within groups & 2008898.2 & 1468.5 & & \\
\hline & all & 2030923.8 & & & \\
\hline \multirow[t]{3}{*}{ GE Board } & between groups & 90708.9 & 22677.2 & 4.988 & $0.001 * * *$ \\
\hline & within groups & 12084746.9 & 4546.6 & & \\
\hline & all & 12175455.7 & & & \\
\hline \multirow[t]{3}{*}{ SME Board } & between groups & 67100.9 & 16775.2 & 6.252 & $0.001 * * *$ \\
\hline & within groups & 8757492.3 & 2683.1 & & \\
\hline & all & 8824593.2 & & & \\
\hline
\end{tabular}

$\mathrm{p}^{*}<0.05, \mathrm{p}^{* *} \leq 0.01, \mathrm{p}^{* * *} \leq 0.001$

Table 9 shows the descriptive statistics of the stock return rates of five utility model grant's innovation continuity groups. For the whole market, SH main board and GE board, the groups 3 seem to have the higher stock return rate means than the other groups. For SZ main board and SME board, the groups 5 seem to have the higher stock return rate means than the other groups. 
Table 9: Descriptive Statistics of Stock Return Rate of Utility Model Grant's Innovation Continuity Groups

\begin{tabular}{|c|c|c|c|c|}
\hline \multirow[b]{2}{*}{ Stock Board } & \multirow[b]{2}{*}{ Group } & \multicolumn{3}{|c|}{ Stock Price Return Rate (\%) } \\
\hline & & Mean & $\begin{array}{l}\text { Standard } \\
\text { Deviation }\end{array}$ & $\begin{array}{c}\text { Standard } \\
\text { Error }\end{array}$ \\
\hline \multirow{5}{*}{$\begin{array}{l}\text { Whole } \\
\text { Market }\end{array}$} & 1 & 3.009 & 45.676 & 1.241 \\
\hline & 2 & 7.896 & 59.596 & 1.738 \\
\hline & 3 & 11.954 & 68.041 & 1.893 \\
\hline & 4 & 7.792 & 53.372 & 1.248 \\
\hline & 5 & 10.163 & 49.193 & 0.622 \\
\hline \multirow{5}{*}{$\begin{array}{l}\text { SH Main } \\
\text { Board }\end{array}$} & 1 & -2.870 & 37.907 & 1.514 \\
\hline & 2 & 4.946 & 52.937 & 2.419 \\
\hline & 3 & 7.100 & 50.387 & 2.193 \\
\hline & 4 & 6.761 & 47.100 & 1.729 \\
\hline & 5 & 6.004 & 45.762 & 0.971 \\
\hline \multirow{5}{*}{$\begin{array}{l}\text { SZ Main } \\
\text { Board }\end{array}$} & 1 & 2.465 & 44.036 & 2.949 \\
\hline & 2 & 1.401 & 37.873 & 3.072 \\
\hline & 3 & -6.525 & 32.589 & 2.858 \\
\hline & 4 & -5.476 & 29.507 & 2.409 \\
\hline & 5 & 4.434 & 39.081 & 1.458 \\
\hline \multirow[t]{5}{*}{ GE Board } & 1 & 17.060 & 55.893 & 3.282 \\
\hline & 2 & 24.075 & 85.972 & 5.352 \\
\hline & 3 & 34.444 & 105.674 & 6.142 \\
\hline & 4 & 17.551 & 73.274 & 3.443 \\
\hline & 5 & 16.087 & 51.078 & 1.382 \\
\hline \multirow{5}{*}{ SME Board } & 1 & 1.760 & 48.959 & 3.347 \\
\hline & 2 & 1.714 & 46.878 & 2.767 \\
\hline & 3 & 6.949 & 54.271 & 2.952 \\
\hline & 4 & 4.356 & 43.916 & 1.994 \\
\hline & 5 & 12.864 & 54.113 & 1.227 \\
\hline
\end{tabular}

Table 10 shows the multiple comparisons of ANOVA on the stock return rate between every two utility model grant's innovation continuity groups. Regarding the whole market, the stock return rate variances between groups 2 and 1, between groups 3 and 1, between groups 4 and 1, between groups 4 and 3, between groups 5 and 1, are of significance; the others are not. The group 1 is therefore confirmed to have the lowest stock return rate mean among all groups according to the significant mean differences. However, the stock return rate ranking of groups 2, 3, 4 and 5, is not provided with significance.

Regarding SH main board, the stock return rate variances between groups 2 and 1 , between groups 3 and 1, between groups 4 and 1, between groups 5 and 1, are of significance; the others are not. The group 1 is therefore confirmed to have the 
lowest stock return rate mean among all groups according to the significant mean differences. However, the stock return rate ranking of groups 2, 3, 4 and 5, is not provided with significance..

Regarding SZ main board, the stock return rate variances between groups 3 and 1, between groups 4 and 1, between groups 5 and 3, between groups 5 and 4, are of significance; the others are not. The group 5 are confirmed to have the highest stock return rate mean among all groups according to the significant mean differences. However, the stock return rate ranking of groups 1, 2, 3 and 4, is not provided with significance.

Regarding GE board, the stock return rate variances between groups 3 and 1, between groups 4 and 3, between groups 5 and 3, are of significance; the others are not. The group 3 is therefore confirmed to have the highest stock return rate mean among all groups according to the significant mean differences. However, the stock return rate ranking of groups 1,2, 4 and 5, is not provided with significance.

Regarding SME board, the stock return rate variances between groups 5 and 1, between groups 5 and 2, between groups 5 and 4, are of significance; the others are not. The group 5 is therefore confirmed to have the highest stock return rate mean among all groups according to the significant mean differences. However, the stock return rate ranking of groups 1,2,3 and 4, is not provided with significance.

According to the above analyses, the utility model grant's innovation continuity shows its particular observing effect on the stock return rate. The innovation continuity group 1 has the lowest stock return rate in the whole market, SH main board and SME board. The innovation continuity group 5 has the highest stock return rate in SZ main board and SME board. The innovation continuity group 3 has the highest stock return rate in GE board.

Table 10: Multiple Comparison of ANOVA on Stock Return Rate between Utility Model Grant's Innovation Continuity Groups

\begin{tabular}{|c|c|c|c|c|c|}
\hline \multirow[b]{2}{*}{ Stock Board } & \multirow{2}{*}{$\begin{array}{c}\text { (I) } \\
\text { Group }\end{array}$} & \multirow[b]{2}{*}{$\begin{array}{c}(\mathrm{J}) \\
\text { Group }\end{array}$} & \multicolumn{3}{|c|}{ Stock Return Rate (\%) } \\
\hline & & & $\begin{array}{c}\text { Mean } \\
\text { Difference (I-J) }\end{array}$ & $\begin{array}{c}\text { Standard } \\
\text { Error }\end{array}$ & $\mathbf{p}$ \\
\hline \multirow[t]{10}{*}{ Whole Market } & 2 & 1 & 4.886 & 2.109 & $0.021 *$ \\
\hline & 3 & 1 & 8.945 & 2.058 & $0.001 * * *$ \\
\hline & 3 & 2 & 4.059 & 2.132 & 0.057 \\
\hline & 4 & 1 & 4.782 & 1.897 & $0.012 *$ \\
\hline & 4 & 2 & -0.104 & 1.977 & 0.958 \\
\hline & 4 & 3 & -4.163 & 1.923 & $0.030 *$ \\
\hline & 5 & 1 & 7.154 & 1.586 & $0.001 * * *$ \\
\hline & 5 & 2 & 2.268 & 1.682 & 0.178 \\
\hline & 5 & 3 & -1.791 & 1.617 & 0.268 \\
\hline & 5 & 4 & 2.372 & 1.406 & 0.092 \\
\hline
\end{tabular}




\begin{tabular}{|c|c|c|c|c|c|}
\hline \multirow{10}{*}{$\begin{array}{l}\text { SH Main } \\
\text { Board }\end{array}$} & 2 & 1 & 7.815 & 2.813 & $0.005 * *$ \\
\hline & 3 & 1 & 9.970 & 2.738 & $0.001 * * *$ \\
\hline & 3 & 2 & 2.155 & 2.925 & 0.461 \\
\hline & 4 & 1 & 9.631 & 2.515 & $0.001 * * *$ \\
\hline & 4 & 2 & 1.816 & 2.717 & 0.504 \\
\hline & 4 & 3 & -0.339 & 2.640 & 0.898 \\
\hline & 5 & 1 & 8.874 & 2.097 & $0.001 * * *$ \\
\hline & 5 & 2 & 1.058 & 2.336 & 0.650 \\
\hline & 5 & 3 & -1.096 & 2.245 & 0.625 \\
\hline & 5 & 4 & -0.757 & 1.966 & 0.700 \\
\hline \multirow{10}{*}{$\begin{array}{l}\text { SZ Main } \\
\text { Board }\end{array}$} & 2 & 1 & -1.064 & 4.031 & 0.792 \\
\hline & 3 & 1 & -8.990 & 4.229 & $0.034 *$ \\
\hline & 3 & 2 & -7.926 & 4.578 & 0.084 \\
\hline & 4 & 1 & -7.941 & 4.047 & $0.050 *$ \\
\hline & 4 & 2 & -6.877 & 4.410 & 0.119 \\
\hline & 4 & 3 & 1.049 & 4.592 & 0.819 \\
\hline & 5 & 1 & 1.968 & 2.938 & 0.503 \\
\hline & 5 & 2 & 3.032 & 3.421 & 0.376 \\
\hline & 5 & 3 & 10.959 & 3.653 & $0.003^{* *}$ \\
\hline & 5 & 4 & 9.909 & 3.440 & $0.004^{*}$ \\
\hline \multirow[t]{10}{*}{ GE Board } & 2 & 1 & 7.015 & 5.771 & 0.224 \\
\hline & 3 & 1 & 17.385 & 5.571 & $0.002 * *$ \\
\hline & 3 & 2 & 10.370 & 5.743 & 0.071 \\
\hline & 4 & 1 & 0.491 & 5.071 & 0.923 \\
\hline & 4 & 2 & -6.524 & 5.259 & 0.215 \\
\hline & 4 & 3 & -16.894 & 5.039 & $0.001 * * *$ \\
\hline & 5 & 1 & -0.973 & 4.360 & 0.823 \\
\hline & 5 & 2 & -7.988 & 4.577 & 0.081 \\
\hline & 5 & 3 & -18.357 & 4.323 & $0.001 * * *$ \\
\hline & 5 & 4 & -1.464 & 3.656 & 0.689 \\
\hline \multirow[t]{10}{*}{ SME Board } & 2 & 1 & -0.046 & 4.678 & 0.992 \\
\hline & 3 & 1 & 5.188 & 4.525 & 0.252 \\
\hline & 3 & 2 & 5.235 & 4.158 & 0.208 \\
\hline & 4 & 1 & 2.596 & 4.251 & 0.541 \\
\hline & 4 & 2 & 2.642 & 3.858 & 0.493 \\
\hline & 4 & 3 & -2.593 & 3.670 & 0.480 \\
\hline & 5 & 1 & 11.103 & 3.731 & $0.003 * *$ \\
\hline & 5 & 2 & 11.149 & 3.275 & $0.001 * * *$ \\
\hline & 5 & 3 & 5.915 & 3.052 & 0.053 \\
\hline & 5 & 4 & 8.507 & 2.629 & $0.001 * * *$ \\
\hline
\end{tabular}

$\mathrm{p}^{*}<0.05, \mathrm{p}^{* *} \leq 0.01, \mathrm{p}^{* * *} \leq 0.001$ 


\subsection{Design Grant}

Table 11 shows the results of ANOVA on the stock return rate between the design grant's innovation continuity groups. The stock return rate variances in the whole market, SZ main board and SME board reach $\mathrm{p}^{* * *} \leq 0.001$ significance, different design grant's innovation continuity groups have significantly different stock return rate means. However, the stock return rate variances in $\mathrm{SH}$ main board and GE board are not of significance.

Table 11: Result of ANOVA on Stock Return Rate Between Design Grant's Innovation Continuity Groups

\begin{tabular}{|c|c|c|c|c|c|}
\hline \multicolumn{2}{|c|}{ Stock Board } & $\begin{array}{c}\text { Sum } \\
\text { Square }\end{array}$ & $\begin{array}{l}\text { Mean } \\
\text { Square }\end{array}$ & $\mathbf{F}$ & $\mathbf{p}$ \\
\hline \multirow{3}{*}{$\begin{array}{l}\text { Whole } \\
\text { Market }\end{array}$} & between groups & 122155.2 & 30538.8 & 11.304 & $0.001 * * *$ \\
\hline & within groups & 20315232.1 & 2701.5 & & \\
\hline & all & 20437387.4 & & & \\
\hline \multirow{3}{*}{$\begin{array}{l}\text { SH Main } \\
\text { Board }\end{array}$} & between groups & 9777.9 & 2444.5 & 1.116 & 0.347 \\
\hline & within groups & 6144862.0 & 2189.9 & & \\
\hline & all & 6154639.9 & & & \\
\hline \multirow{3}{*}{$\begin{array}{l}\text { SZ Main } \\
\text { Board }\end{array}$} & between groups & 73935.0 & 18483.7 & 11.570 & $0.001 * * *$ \\
\hline & within groups & 1407482.9 & 1597.6 & & \\
\hline & all & 1481417.8 & & & \\
\hline \multirow[t]{3}{*}{ GE Board } & between groups & 22031.6 & 5507.9 & 1.460 & 0.212 \\
\hline & within groups & 6373558.9 & 3771.3 & & \\
\hline & all & 6395590.5 & & & \\
\hline \multirow[t]{3}{*}{ SME Board } & between groups & 109326.6 & 27331.7 & 9.450 & $0.001 * * *$ \\
\hline & within groups & 6154452.0 & 2892.1 & & \\
\hline & all & 6263778.6 & & & \\
\hline
\end{tabular}

$\mathrm{p}^{*}<0.05, \mathrm{p}^{* *} \leq 0.01, \mathrm{p}^{* * *} \leq 0.001$

Table 12 shows the descriptive statistics of the stock return rates of five design grant's innovation continuity groups. For the whole market and most stock boards except SH main board, the groups 5 seem to have the higher stock return rate means than the other groups. For SH main board, the group 4 seems to have the higher stock return rate mean. 
Table 12: Descriptive Statistics of Stock Return Rate of Design Grant's Innovation Continuity Groups

\begin{tabular}{|l|c|c|c|c|}
\hline \multirow{3}{*}{ Patent Species } & Group & \multicolumn{3}{|c|}{ Stock Return Rate (\%) } \\
\cline { 2 - 5 } & & Mean & $\begin{array}{c}\text { Standard } \\
\text { Deviation }\end{array}$ & $\begin{array}{c}\text { Standard } \\
\text { Error }\end{array}$ \\
\hline Whole Market & 1 & 7.813 & 49.901 & 1.070 \\
\cline { 2 - 5 } & 2 & 5.159 & 45.332 & 1.225 \\
\cline { 2 - 5 } & 3 & 8.585 & 57.642 & 1.736 \\
\cline { 2 - 5 } & 4 & 10.981 & 50.445 & 1.544 \\
\cline { 2 - 5 } & 5 & 16.498 & 56.205 & 1.321 \\
\hline SH Main Board & 1 & 6.056 & 47.971 & 1.595 \\
\cline { 2 - 5 } & 2 & 3.933 & 45.908 & 1.987 \\
\cline { 2 - 5 } & 3 & 5.261 & 41.527 & 2.061 \\
\cline { 2 - 5 } & 4 & 9.724 & 52.400 & 2.854 \\
\cline { 2 - 5 } & 5 & 8.263 & 45.854 & 1.827 \\
\hline SZ Main Board & 1 & -2.653 & 36.684 & 2.228 \\
\cline { 2 - 5 } & 2 & -6.723 & 26.931 & 2.116 \\
\cline { 2 - 5 } & 3 & 3.879 & 43.399 & 4.340 \\
\cline { 2 - 5 } & 4 & 11.489 & 53.757 & 5.149 \\
\cline { 2 - 5 } & 5 & 16.362 & 42.008 & 2.689 \\
\hline GE Board & 1 & 18.170 & 53.419 & 2.538 \\
\cline { 2 - 5 } & 2 & 15.121 & 55.295 & 3.026 \\
\cline { 2 - 5 } & 3 & 15.905 & 87.358 & 5.148 \\
\cline { 2 - 5 } & 4 & 10.120 & 48.655 & 2.882 \\
\cline { 2 - 5 } & 5 & 21.452 & 59.835 & 3.221 \\
\hline & 1 & 7.521 & 54.151 & 2.292 \\
\cline { 2 - 5 } & 2 & 2.951 & 38.248 & 2.077 \\
\cline { 2 - 5 } & 3 & 7.649 & 42.737 & 2.435 \\
\cline { 2 - 5 } & 4 & 12.803 & 48.986 & 2.668 \\
\hline & 5 & 22.441 & 67.142 & 2.762 \\
\hline
\end{tabular}

Table 13 shows the multiple comparisons of ANOVA on the stock return rate between every two design grant's innovation continuity groups. Regarding the whole market, the stock return rate variances between groups 4 and 2, between groups 5 and 1, between groups 5 and 2, between groups 5 and 3, between groups 5 and 4 , are of significance; the others are not. The group 5 is confirmed to have the highest stock return rate mean among all groups according to the significant mean differences. However, the stock return rate ranking of groups 1, 2, 3 and 4, is not provided with significance.

Regarding SH main board, as shown in Tables 11 and 13, the stock return rate variances between any two groups are not of significance. The stock return rates in groups 1, 2, 3, 4 and 5, do not show significant difference. 
Regarding SZ main board, the stock return rate variances between groups 3 and 2, between groups 4 and 2, between groups 5 and 1, between groups 5 and 2, between groups 5 and 3, are of significance; the others are not. The groups 4 and 5 are therefore confirmed to have the higher stock return rate means among all groups according to the significant mean differences. However, the stock return rate ranking of groups 1,2 , and 3 , is not provided with significance.

Regarding GE board, as shown in Tables 11 and 13, the stock return rate variance is only of significance between groups 5 and 4; whereas the stock return rate variances between any other two groups are not of significance.

Regarding SME board, the stock return rate variances between groups 4 and 2, groups 5 and 1, between groups 5 and 2, between groups 5 and 3, between groups 5 and 4, are of significance; the others are not. The group 5 is therefore confirmed to have the highest stock return rate mean among all groups according to the significant mean differences. However, the stock return rate ranking of groups 1, 2, 3 and 4 , is not provided with significance.

According to the above analyses, the design grant's innovation continuity is a good indicator for observing the stock return rate in the whole market, SZ main board and SME board.

Table 13: Multiple Comparisons of ANOVA on Stock Return Rate between Design Grant's Innovation Continuity Groups

\begin{tabular}{|c|c|c|c|c|c|}
\hline \multirow{2}{*}{ Stock Board } & \multirow{2}{*}{ (I) Group } & \multirow{2}{*}{ (J) Group } & \multicolumn{3}{|c|}{ Stock Return Rate (\%) } \\
\hline & & & Mean Difference (I-J) & Standard Error & $\mathbf{p}$ \\
\hline \multirow[t]{10}{*}{ Whole Market } & 2 & 1 & -2.655 & 1.793 & 0.139 \\
\hline & 3 & 1 & 0.772 & 1.922 & 0.688 \\
\hline & 3 & 2 & 3.426 & 2.104 & 0.103 \\
\hline & 4 & 1 & 3.168 & 1.942 & 0.103 \\
\hline & 4 & 2 & 5.823 & 2.122 & $0.006 * *$ \\
\hline & 4 & 3 & 2.396 & 2.232 & 0.283 \\
\hline & 5 & 1 & 8.685 & 1.653 & $0.001 * * *$ \\
\hline & 5 & 2 & 11.340 & 1.862 & $0.001 * * *$ \\
\hline & 5 & 3 & 7.913 & 1.986 & $0.001 * * *$ \\
\hline & 5 & 4 & 5.517 & 2.005 & $0.006 * *$ \\
\hline \multirow[t]{10}{*}{ SH Main Board } & 2 & 1 & -2.123 & 2.554 & 0.406 \\
\hline & 3 & 1 & -0.794 & 2.796 & 0.776 \\
\hline & 3 & 2 & 1.328 & 3.081 & 0.666 \\
\hline & 4 & 1 & 3.668 & 2.987 & 0.220 \\
\hline & 4 & 2 & 5.790 & 3.256 & 0.075 \\
\hline & 4 & 3 & 4.462 & 3.448 & 0.196 \\
\hline & 5 & 1 & 2.207 & 2.429 & 0.363 \\
\hline & 5 & 2 & 4.330 & 2.753 & 0.116 \\
\hline & 5 & 3 & 3.002 & 2.978 & 0.314 \\
\hline & 5 & 4 & -1.460 & 3.158 & 0.644 \\
\hline
\end{tabular}




\begin{tabular}{|c|c|c|c|c|c|}
\hline \multirow[t]{10}{*}{ SZ Main Board } & 2 & 1 & -4.071 & 3.969 & 0.305 \\
\hline & 3 & 1 & 6.531 & 4.677 & 0.163 \\
\hline & 3 & 2 & 10.602 & 5.083 & $0.037^{*}$ \\
\hline & 4 & 1 & 14.141 & 4.533 & $0.002 * *$ \\
\hline & 4 & 2 & 18.212 & 4.952 & $0.001 * * *$ \\
\hline & 4 & 3 & 7.610 & 5.535 & 0.169 \\
\hline & 5 & 1 & 19.015 & 3.527 & $0.001 * * *$ \\
\hline & 5 & 2 & 23.085 & 4.051 & $0.001 * * *$ \\
\hline & 5 & 3 & 12.483 & 4.746 & $0.009 * *$ \\
\hline & 5 & 4 & 4.873 & 4.605 & 0.290 \\
\hline \multirow[t]{10}{*}{ GE Board } & 2 & 1 & -3.048 & 4.450 & 0.493 \\
\hline & 3 & 1 & -2.265 & 4.648 & 0.626 \\
\hline & 3 & 2 & 0.783 & 4.938 & 0.874 \\
\hline & 4 & 1 & -8.050 & 4.663 & 0.084 \\
\hline & 4 & 2 & -5.002 & 4.952 & 0.313 \\
\hline & 4 & 3 & -5.785 & 5.131 & 0.260 \\
\hline & 5 & 1 & 3.282 & 4.410 & 0.457 \\
\hline & 5 & 2 & 6.330 & 4.714 & 0.180 \\
\hline & 5 & 3 & 5.547 & 4.902 & 0.258 \\
\hline & 5 & 4 & 11.332 & 4.916 & $0.021 *$ \\
\hline \multirow[t]{10}{*}{ SME Board } & 2 & 1 & -4.570 & 3.703 & 0.217 \\
\hline & 3 & 1 & 0.127 & 3.817 & 0.973 \\
\hline & 3 & 2 & 4.697 & 4.233 & 0.267 \\
\hline & 4 & 1 & 5.281 & 3.710 & 0.155 \\
\hline & 4 & 2 & 9.852 & 4.137 & $0.017 *$ \\
\hline & 4 & 3 & 5.154 & 4.239 & 0.224 \\
\hline & 5 & 1 & 14.920 & 3.174 & $0.001 * * *$ \\
\hline & 5 & 2 & 19.490 & 3.664 & $0.001 * * *$ \\
\hline & 5 & 3 & 14.792 & 3.779 & $0.001 * * *$ \\
\hline & 5 & 4 & 9.638 & 3.671 & $0.009 * *$ \\
\hline
\end{tabular}

$\mathrm{p}^{*}<0.05, \mathrm{p}^{* *} \leq 0.01, \mathrm{p}^{* * *} \leq 0.001$

\subsection{Cross Comparison}

Since the innovation continuity groups 5 of all patent species seem to have the higher stock return rates, Table 14 shows the results of ANOVA on the stock return rate between all patent species' innovation continuity groups 5 regarding the whole market. The stock return rate variance reaches $\mathrm{p}^{* * *} \leq 0.001$ significance, different patent species' innovation continuity groups 5 have significantly different stock return rate means. 
Table 14: Result of ANOVA on Stock Return Rate Between Four Patent Species' Innovation Continuity Groups 5

\begin{tabular}{|c|c|c|c|c|}
\hline & Sum Square & Mean Square & F & p \\
\hline between groups & 64655.9 & 21552.0 & 8.330 & $0.001 * * *$ \\
\hline within groups & 50595738.4 & 2587.4 & & \\
\hline all & 50660394.3 & & & \\
\hline
\end{tabular}

Table 15 shows the descriptive statistics of the stock return rates of four patent species' innovation continuity groups 5 regarding the whole market, wherein, the groups $51,52,53$, and 54 respectively represent the innovation continuity groups 5 of the invention publication, the invention grant, the utility model grant, and the design grant. The group 53 of the utility model grant seems to have the lower stock return rate and the group 54 the design grant seems to have the higher stock return rate.

Table 15: Descriptive Statistics of Stock Return Rate of Four Patent Species's Innovation Continuity Groups 5

\begin{tabular}{|c|c|c|c|c|}
\hline \multirow{2}{*}{ Group } & \multirow{2}{*}{ Effective Samples } & \multicolumn{3}{|c|}{ Stock Price Return Rate (\%) } \\
\cline { 3 - 5 } & & Mean & Standard Deviation & Standard Error \\
\hline 51 & 6353 & 12.853 & 50.604 & 0.635 \\
\hline 52 & 5148 & 12.978 & 51.209 & 0.714 \\
\hline 53 & 6248 & 10.163 & 49.193 & 0.622 \\
\hline 54 & 1810 & 16.498 & 56.205 & 1.321 \\
\hline
\end{tabular}

Table 16 shows the multiple comparisons of ANOVA on the stock return rate between every two innovation continuity groups 5 regarding the whole market. The stock return rate variance is not of significance only between groups 52 and 51, the other stock return rate variances are of significance. According to the significant mean differences, the design grant's innovation continuity group 5 has the highest stock return rate mean, the utility model grant's innovation continuity group 5 has the lowest stock return rate. In addition, the innovation continuity groups 5 of the invention publication and the invention grant do not have significantly different stock return rates. 
Table 16: Multiple Comparisons of ANOVA on Stock Return Rate between Four Patent Species's Innovation Continuity Groups 5

\begin{tabular}{|c|c|c|c|c|}
\hline \multirow{2}{*}{$(\mathbf{I})$ Group } & \multirow{2}{*}{$(J)$ Group } & \multicolumn{3}{|c|}{ Stock Return Rate (\%) } \\
\cline { 3 - 5 } & & Mean Difference (I-J) & Standard Error & p \\
\hline 52 & 51 & 0.125 & 0.954 & 0.896 \\
\hline 53 & 51 & -2.690 & 0.906 & $0.003^{* *}$ \\
\hline 53 & 52 & -2.815 & 0.957 & $0.003^{* *}$ \\
\hline 54 & 51 & 3.645 & 1.355 & $0.007^{*}$ \\
\hline 54 & 52 & 3.520 & 1.390 & $0.011^{*}$ \\
\hline 54 & 53 & 6.335 & 1.358 & $0.001^{* *} *$ \\
\hline
\end{tabular}

$\mathrm{p}^{*}<0.05, \mathrm{p}^{* *} \leq 0.01, \mathrm{p}^{* * *} \leq 0.001$

\section{Conclusion and Recommendation}

Four quarter's stock return rates in 2020 of China A-shares listed in four stock boards and the patent data of four patent species including the invention publication, the invention grant, the utility model grant, and the design grant, over previous five years were collected. The variances of the stock return rate via different innovation continuity which representing by the patent publication frequency over previous five years were analyzed via ANOVA. The following conclusions were arrived:

1. Regarding the whole market, SZ main board and SME board, the innovation continuity of any patent species was a good indicator for observing the stock return rate. The A-shares with the stronger innovation continuity usually showed the higher stock return rate and the A-shares with the weaker innovation continuity usually showed the lower stock return rate. However, it was not appropriate to exactly rank the stock return rate by the innovation continuity because the ranking relationship is not provided with significance.

2. Regarding SH main board, the innovation continuity of any of the invention publication, the invention grant, and the utility model grant was a good indicator for observing the stock return rate; whereas the innovation continuity of the design grant is not. The A-shares with the stronger innovation continuity usually showed the higher stock return rate. Regarding GE board, the innovation continuity of the utility model grant was a good indicator for observing the stock return rate; whereas the innovation continuity of any other patent species is not. The A-shares in $\mathrm{SH}$ board and GE board with the stronger innovation continuity of specific patent species usually showed the higher stock return rate. However, it was also not appropriate to exactly rank the stock return rate by the abovementioned innovation continuity because the ranking relationship is not provided with significance either. 3. Considering the patent species, the innovation continuity of the utility model grant was the indicator of the highest applicability. It could be applied for the whole market and any stock board. However, the utility model grant's strongest innovation continuity group had the lowest stock return rate mean when comparing with the strongest innovation continuity groups of the other patent species.

4. In addition, the design grant's strongest innovation continuity group had the 
highest stock return rate mean among all patent species' strongest innovation continuity groups though the design grant was usually regarded as the most valueless patent species in China. The investors and the evaluation institutes were suggested to pay more attention on the design grant and the A-shares with design grant patents from now on.

5. The invention grant was always regarded as the most valuable patent species around the world, yet the stock return rate variance between the strongest innovation continuity groups of the invention grant and the invention publication was not significantly different. In China, the invention grant has much longer examination duration which being calculated from the filing date to the issue date, the time lag was long. Since there was no significantly difference in the stock return rate variance between the strongest innovation continuity groups of the invention grant and the invention publication, the invention publication's innovation continuity was more recommended to apply for observation rather than the invention grant's innovation continuity.

The finding of this research would improve the state of the art in the patent valuation and the listed company evaluation.

\section{ACKNOWLEDGEMENTS}

The authors would like to thank the financial support from the Ministry of Science and Technology, Taiwan, R.O.C. under Grant no. MOST 109-2410-H-011-021MY3. 


\section{References}

[1] Dang, J. and Motohashi, K. (2015). Patent statistics: A good indicator for innovation in China? Patent subsidy program impacts on patent quality.

China Economic Review, 35 (Sep), 2015, pp. 137-155. https://doi.org/10.1016/J.CHIECO.2015.03.012.

[2] He, Z.L., Tong, T.W., Zhang, Y. and He, W. (2016).Constructing a Chinese patent database of listed firms in China: Descriptions, lessons, and insights. Journal of Economics \& Management Strategy, 27(3), pp. 579 - 606. https://doi.org/10.1111/jems.12186.

[3] Chen, T.M., Wei, C.C. and Che, H.C. (2018). Contribution of Patent Indicators to China Stock Performance. Proceedings of the IEEE 7th International Congress on Advanced Applied Informatics (ICAAI2018). Yonago, Japan, pp. $793-798$.

[4] Chiu, Y.J., Chen, K.C. and Che, H.C. (2020). Does Patent Help to Build Investment Portfolio of China A-Shares under China-US Trade Conflict?. Mathematical Problems in Engineering, ID 7317480, https://doi.org/10.1155/2020/7317480

[5] Chiu, Y.J., Chen, K.C. and Che, H.C. (2020). Patent implemented time series algorithm for building stock portfolios in China A-Shares. Asian Journal of Information and Communications, 12(1), pp. $156-170$.

[6] Chiu, Y.J., Chen, K.C. and Che, H.C. (2020). Using Patent to Predict BookValue-Per-Share and Investment -- Evidence in China A-Shares. International Journal of Innovation in Management, 8(2), pp. 47 - 64.

[7] Chiu, Y.J., Chen, K.C. and Che, H.C. (2020). Patent As Predictive Indicator of Investment: An Empirical Study of China A-Shares. Proceedings of the 2020 Chinese Society for Management of Technology Conference, Hsinchu, Taiwan.

[8] Chiu, Y.J., Chen, K.C. and Che, H.C. (2020). Patent Informatics in Predicting Stock Price and Increasing Investment Performance -- An Empirical Study of China Four Stock Boards. Proceedings of the 2020 International Conference on Economics, Management and Technology (IEMT2020), Kaohsiung, Taiwan.

[9] Chiu, Y.J., Chen, K.C. and Che, H.C. (2020). Patent Informatics in Predicting Return-on-Assets (ROA) and Increasing Investment Performance in China. Proceedings of the 2020 International Conference on Business Administration - Fall Session (ICBA 2020 Fall), New Taipei City, Taiwan.

[10] Chiu, Y.J., Chen, K.C. and Che, H.C. (2021). Patent predictive price-to-book ratio $(\mathrm{PB})$ on improving investment performance -- Evidence in China. World Patent Information, ID 102039. https://doi.org/10.1016/j.wpi.2021.102039

[11] Li, Z., Deng, G. and Che, H.C. (2020). Patent-Based Predictive ROE on Increasing Investment Performance of China Stock Market. Proceedings of the 2020 IEEE International Conference on Computer and Communications (ICCC2020), Chengdu, China. 
[12] Li, Z., Deng, G. and Che, H.C. (2020). Patent-Based Predictive Price-toEarnings on Increasing Investment Performance of China Stock Market. Proceedings of the 2020 International Symposium on Computational Intelligence and Design (ISCID2020), Hangzhou, China.

[13] Li, Z., Deng, G. and Che, H.C. (2021). Patent-Based Predictive EPS on Increasing Investment Performance of China Stock Market. Proceedings of the 2021 IEEE International Conference on Power Electronics, Computer Applications (ICPECA2021), Shenyang, China.

[14] Tsai, H.W., Che, H.C. and Bai, B. (2021). Patent Effects on Higher Stock Price and Higher Return Rate - A Study in China Stock Market. Proceedings of the International Conference on Innovation and Management (IAM2021), Taiwan.

[15] Deng, D., Lev, B. and Narin, F. (1999). Science and technology as predictors of stock performance. Financial Analysts Journal, 55(3), 1999, pp. 20 - 32.

[16] Thomas, P. (2001). A relationship between technology indicators and stock market performance. Scientometrics, 55(1), pp. 319 - 333. 